In conjunction with the Incoterms 1980, the ICC has also published a Guide to Incoterms which illustrates with practical examples the circumstances in which each provision of the Incoterms applies and what the consequences of its application are.

In the United States, these publications are available from:

ICC Publishing Corporation, Inc.

1212 Avenue of the Americas

New York, New York 10036

Incoterms 1980 is priced at U.S. \$5.00, and Guide to Incoterms at U.S. $\$ 8.75$.

\title{
SURVEY OF SUBSCRIPTION COSTS \\ TO CANADIAN LEGAL PUBLICATIONS
}

As reported in the May-July 1980 (Vol. 5, No. 5, N.S.) issue of the Canadian Association of Law Libraries Newsletter, costs of Canadian legal publications keep climbing at a rate parallel to that of many other countries. Prepared by Pat LaVac, University of British Columbia, at the request of Frank Winter, Chairman of the C.A.L.L. Statistics Committee, the report contains 1979 subscription rates of some 250 Canadian legal serials.

The comparative costs for 1978 and 1979 are of special interest:

Comparative Costs and Percentages Increase FOR YEARS

1978-1979

1978

1979

Number

Number Average Increase

of Average of Unit Per Percentage

Titles Unit Cost Titles Cost Unit Increase

Journals

$61 \quad 22.18$

$68 \quad 25.22 \quad 3.04$

$13.71 \%$

Looseleaf

Services

$75 \quad 100.45$

Reports

$32 \quad 64.57$

Statues

$29 \quad 22.90$

Miscellaneous

$41 \quad 33.85$

$\begin{array}{lr}82 & 107.10 \\ 33 & 67.00 \\ 31 & 26.84 \\ 42 & 40.40\end{array}$

6.65

$6.62 \%$

$2.43 \quad 3.76 \%$

$3.94 \quad 17.21 \%$

$6.55 \quad 19.35 \%$

Overall average increase : $12.13 \%$ 